\title{
Influence of mechanochemical processing to luminescence properties in Y2O3 powder
}

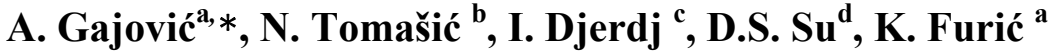 \\ ${ }^{a}$ Ruđer Bođković Institute, P.O. Box 180, HR-10002 Zagreb, Croatia \\ ${ }^{\mathrm{b}}$ Institute of Mineralogy and Petrography, Faculty of Science, University of Zagreb, Horvatovac bb, HR- \\ 10000 Zagreb, Croatia \\ ${ }^{c}$ Department of Physics, Faculty of Science, University of Zagreb, P.O. Box 331, HR-10002 Zagreb, \\ Croatia \\ ${ }^{\mathrm{d}}$ Fritz Haber Institute of the Max Planck Society, Faradayweg 4-6, 14195 Berlin, Germany
}

* Corresponding author. Tel.: +385 1 4561106; fax: +385 1 4680112,E-mail address: gajovic@irb.hr (A. Gajović).

\begin{abstract}
In high purity $\mathrm{Y}_{2} \mathrm{O}_{3}$ powders presence of small amount of erbium ions in cation sites was identified due to the luminescence bands observed by Raman spectrometer. The decrease of the luminescence intensity during high-energy ball-milling was explained. The mechanochemical processing induced the changes of $\mathrm{Y}_{2} \mathrm{O}_{3}$ microstructure introducing distortion of the crystal lattice and oxygen vacancies in the cubic phase, substitution of tungsten at the cation sites in $\mathrm{c}-\mathrm{Y}_{2} \mathrm{O}_{3}$, and incomplete phase transition of $\mathrm{Y}_{2} \mathrm{O}_{3}$ from the cubic to the monoclinic structure. The influence of the particle-size decrease, caused by ball-milling, to luminescence was also considered.
\end{abstract}

Keywords: Oxide materials; Mechanochemical processing; Microstructure; Luminescence

\section{Introduction}

Yttrium sesquioxide $\left(\mathrm{Y}_{2} \mathrm{O}_{3}\right)$ ceramics have been intensively investigated for different technological purposes. For decades yttrium oxide has been an important material in ceramic industry, from constituent of ceramic superconductors [1,2], to wellknown YSZ ceramics [3,4]. $\mathrm{Y}_{2} \mathrm{O}_{3}$ is also used in electronic applications as a part of metal-oxide-semiconductor heterostructures in MOS transistors [5-8]. It also plays an important role in preparation of novel light-emitting materials. $\mathrm{Y}_{2} \mathrm{O} 3$ is used as a refractory matrix in rare earth ion doped laser materials [9]. It is selected as a host because of favorable thermomechanical properties (high melting point, phase stability, low thermal expansion). A very good substitution of dopants is insured by similar crystal-chemical constraints for rare earth ions and yttrium $[9,10]$.

$\mathrm{Y}_{2} \mathrm{O}_{3}$ structure corresponds to the C-type cubic bixbyite structure, space group Ia3 [11,12] with 16 formula units in the elementary cell. There are 32 cation (six-fold coordinated) sites available for substitution of lanthanide ions: eight are centrosymmetric with $C 3 \mathrm{i}$ symmetry and 24 noncentrosymmetric with $C_{2}$ symmetry (Fig. 1a). The sites with $C_{3 \mathrm{i}}$ symmetry have a smaller crystal field, so Stark splitting of $4 \mathrm{f}$ orbital is smaller [13]. Moreover, since $C_{3 \mathrm{i}}$ site has an inversion center, the selection rules forbid the electron-dipole (ED) transitions, but thermal fluctuations of $\mathrm{Y}_{2} \mathrm{O}_{3}$ lattice destroy the perfect $C_{3 i}$ symmetry locally [14], and the ED transitions can occur. There is no center of inversion in the $C_{2}$ site and the luminescence of incorporated lanthanide ions is predominantly connected with this site. At the pressure of 10-13 GPa cubic $\mathrm{Y}_{2} \mathrm{O}_{3}$ exhibits the first-order reconstructive (irreversible) phase transition [15] to monoclinic structure, space group $C 2 / m$ [16]. Monoclinic structure has $6 \mathrm{Y}_{2} \mathrm{O}_{3}$ formula units in the elementary cell with 3 nonequivalent cation sites (seven-fold coordinated) and $C$ s symmetry (Fig. 1b). Bihari et. al [17] observed three sets of luminescence lines in doped monoclinic $\mathrm{Y}_{2} \mathrm{O}_{3}$, which correspond to three nonequivalent cation sites.

In this work the luminescence bands was observed in high purity $\mathrm{Y}_{2} \mathrm{O}_{3}(99.99 \%)$. The origin of the luminescence bands was identified and their properties were correlated to the changes of the microstructure. The ball-milling process was used as a method for inducing microstructure transformation and to introduce the strain at the nanometric scale. X-ray diffraction, transmission electron microscopy (TEM), and selected area electron diffraction (SAED) were used to investigate structural changes that influenced the luminescence properties. 


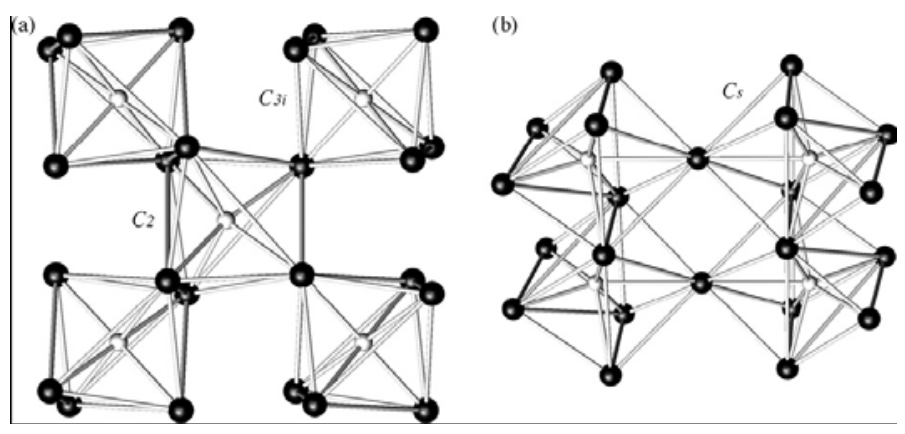

Fig. 1. Cation sites in (a) cubic bixbyite structure, space group $I a 3$ and (b) monoclinic structure, space group $C 2 / \mathrm{m}$.

\section{Experimental}

The luminescence bands were observed in high purity commercially available powders of cubic (c-) $\mathrm{Y}_{2} \mathrm{O}_{3}$ (purity 99.99\%). It was used as starting material for ball-milling experiments. The milling of the powder was performed in air, using Fritsch planetary ball mill "Pulverisette 7" with vial and balls made of tungsten carbide. Powder-to-ball weight ratio was 1:50 and the milling time varied from $1 \mathrm{~min}$ to $3 \mathrm{~h}$.

Spectroscopy was performed using computerized Raman spectroscopy (RS) system, DILOR Z24 triple monochromator with Coherent INNOVA 100 argon ion laser, operating at $514.5 \mathrm{~nm}$ and $488.1 \mathrm{~nm}$ lines for excitation. An Anaspec's doublepass prism premonochromator was used to reduce parasite laser plasma lines. Laser power of $100 \mathrm{~mW}$ was applied. To reduce the heating of the sample during the recording of the spectra, the incident laser beam was focused in the line shape.

The XRD data were obtained on Philips PW 3040/60 X'Pert PRO powder diffractometer using Cu K_ radiation $(\lambda=1.54055 \AA)$ at $45 \mathrm{kV}$ and $40 \mathrm{~mA}$. The incident beam was passed through an X-ray mirror having divergence slit of $1 / 2^{\circ}$. The diffracted beam was directed to the detector through a parallel plate collimator with equatorial acceptance angle of $0.18^{\circ}$. The powdered samples were mounted on a single silicon crystal disc cut in a way of avoiding lattice planes, and thus providing no silicon diffraction and low background. The disc with a samplewas inserted into the sample spinner programmed to the revolution time of one second. Step sizewas set to $0.02^{\circ}$ with measuring time of two seconds per step.

The structural and microstructural parameters were extracted using Rietveld refinement [18] with the program FULLPROF [19]. The scale factor, the background coefficients, the zero point of the detector, and the unit cell parameters were simultaneously refined, followed by the refinement of the Gaussian half width parameters, $U, V, W$, and the Lorentzian half width parameters, $X, Y$. These parameters define the diffraction profile function, which was chosen to be the modified Thompson-Cox-Hastings pseudo-Voigt (T-C-H pV) [20], making the size-microstrain analysis straightforward. The crystal structure was refined in the space group of cubic $\mathrm{Y}_{2} \mathrm{O}_{3} \mathrm{Ia} 3$ (206), and monoclinic $\mathrm{Y}_{2} \mathrm{O}_{3} C 2 / m$ (12). The refinement incorporated weights $w \mathrm{i}$ based on the observed step intensities $Y_{\mathrm{i}}, w_{\mathrm{i}}=1 / Y_{\mathrm{i}}$. The refinement was continued until the shift in any parameter, $\Delta x_{i}$, was less than one third of its estimated standard deviation, $\sigma$ i. The quality of Rietveld refinement was evaluated in terms of the discrepancy factor (weighted residual error), $R_{\mathrm{wp}}$, Bragg discrepancy factor, $R \mathrm{~B}$, and the goodness-of-fit indicator, GoF. The determination of the volumeweighted average grain sizes $(D)$ and the r.m.s. lattice microstrain $\left(\left[\varepsilon^{2} h k l\right]^{1 / 2}\right)$ was achieved by the linebroadening analysis. The instrumental contribution to the peak broadening was removed by the deconvolution method with crystalline NIST SRM 660a as standard.

TEM, SAED were performed on a Philips CM200 $\mathrm{LaB}_{6}$ microscope. High resolution TEM (HRTEM) images were recorded on a Philips CM200 FEG microscope with field emission gun. Both TEMs were operated at $200 \mathrm{kV}$. For TEMmeasurements the samples were first suspended in chloroform, then treated in an ultrasonic bath, mounted onto the carbon-coated copper grids, and finally dried in air. HRTEM images were analyzed by Digital Micorgraph software [21]. When taking SAED patterns, the diameter of the selected area was 40 or $200 \mathrm{~nm}$. The software Process Diffraction [22] was used to determine the interplanar spacing $d$ from the diffraction patterns.

\section{Results}

The luminescence bands were observed in high purity $\mathrm{Y}_{2} \mathrm{O}_{3}$ powders by Raman spectrometer with visible excitation. The luminescence nature of the bands is the most easily detectable by comparison of band positions when $488 \mathrm{~nm}\left(20492.4 \mathrm{~cm}^{-1}\right)$ and $514.5 \mathrm{~nm}\left(19435.1 \mathrm{~cm}^{-1}\right)$ excitation lines are used. When the excitation is changed to a different wavelength the Raman bands shift the same amount correspondingly, 
while the luminescence lines stay on the same absolute wave number (Fig. 2). The bands identified as luminescence were very sharp and narrow, characteristic for $4 \mathrm{f}$ orbital electron transitions in rare earth elements (REE) [23]. Existence of luminescence in the spectra indicated the presence of the REE ions in the crystal lattice even if the declared purity of the samples is high.

The spectra of three $\mathrm{Y}_{2} \mathrm{O}_{3}$ powders (of different producers, but all having the purity of 99.99\%) observed by RS instrument are displayed in Fig. 3. Together with Raman bands characteristic for cubic phase of $\mathrm{Y}_{2} \mathrm{O}_{3}$, in spectra of all powders luminescence lines in region from 515 to $570 \mathrm{~nm}$ were observed after excitation with $514.5 \mathrm{~nm}$. Since no luminescence is observed by RS from pure $\mathrm{Y}_{2} \mathrm{O}_{3}$ in the same spectral region [24], the occurrence of luminescence lines in the studied powders was related to the presence of very small amount of REE ions substituted in the cation sites of $\mathrm{Y}_{2} \mathrm{O}_{3}$ crystal lattice.

The effect of mechanical treatment on the luminescence is significant. After only one minute of milling in a high-energy ball mill, the luminescence part in the spectrum decreases drastically. After 10 min ballmilling, only the luminescence band near $539.5 \mathrm{~nm}$ was observed, while no luminescence can be detected in samples milled $1 \mathrm{~h}$ or longer (Fig. 4). The partial phase transition to monoclinic structure was observed by XRD during and to milling (as will be shown later). The luminescence of REE ions in monoclinic (m-) $\mathrm{Y}_{2} \mathrm{O}_{3}$ has been reported in literature [17] in the spectral range between 525 and $640 \mathrm{~nm}$, but in our 180 min milled sample the luminescence bands were not observed even in large spectral region (from 514.5 to $837.9 \mathrm{~nm}$ ). In spite of the partial phase transition to monoclinic phase, the most intensive Raman band of cubic phase $\left(381 \mathrm{~cm}^{-1}\right.$ for untreated sample)was present in all spectra (Fig. 4). This band is shifted to the lower wave numbers and broadened with prolonged milling (Table 1).

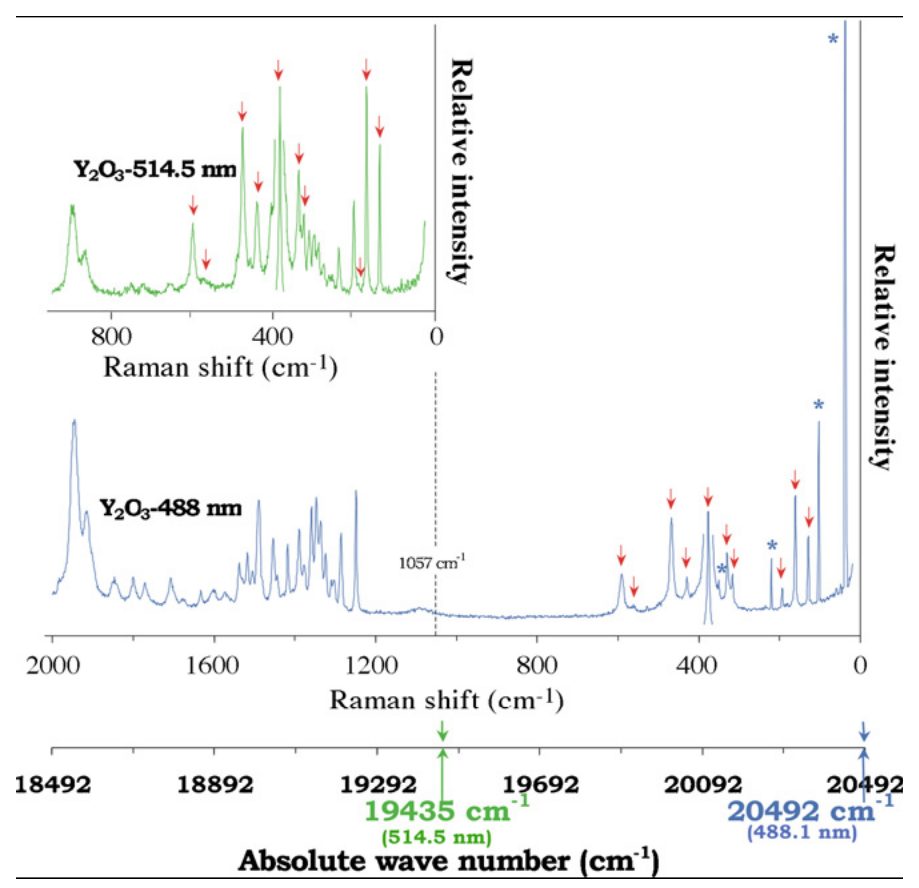

Fig. 2. Comparison of Raman and luminescent spectra upon excitation with 514.5 and $488.1 \mathrm{~nm}$ Ar line. Red arrows are pointed to Raman bands, other bands are luminescence. * represents parasite laser plasma lines.

The shift indicates the increase of the bond lengths, while the broadening indicates the disorder within the oxygen sublattice and the appearance of oxygen vacancies which caused Raman scattering from points of the Brillouin zone with $q \neq 0$ [25].

The XRD powder patterns of untreated and milled $\mathrm{Y}_{2} \mathrm{O}_{3}$ samples are shown in Fig. 5, while structural data calculated by Rietveld refinement are shown in Table 2. The calculated lattice parameter for cubic bixbyite-like structure (space group Ia3) of untreated material is somewhat smaller than $10.6041 \AA$ $\left(\mathrm{Y}_{2} \mathrm{O}_{3}\right.$ : PDF 41-1105) [26]. Since the ionic radius of erbium ion $(0.89 \AA)$ is smaller than ionic radius of yttrium $(0.90 \AA)$, smaller lattice parameter is in agreement with substitution of $\mathrm{Er}$ in cation sites. The Rietveld refinement for 1 min milled sample identified only cubic bixbyite-like structure, space group Ia 3 (Table 2). However, the increase of average maximum microstrain and increase of lattice parameter after only 1 min of treatment was observed. The impact of milling on the samples becomes significant after 10 


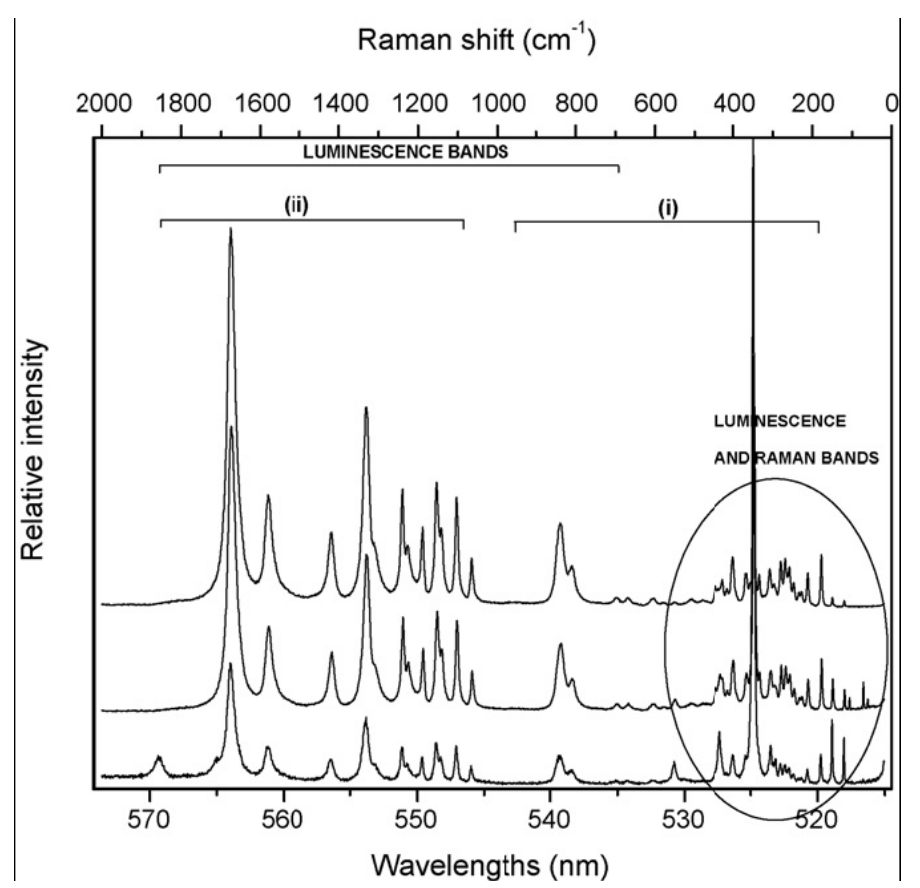

Fig. 3. Raman and luminescence spectra of three different $\mathrm{Y}_{2} \mathrm{O}_{3}$ samples (all with purity $99.99 \%$ ) upon excitation with $514.5 \mathrm{~nm}$ Ar line. Assignment of the luminescence bands [9]: (i) ${ }^{2} \mathrm{H}_{11 / 2} \rightarrow{ }^{4} \mathrm{I}_{15 / 2}$; (ii) ${ }^{4} \mathrm{~S}_{3 / 2} \rightarrow{ }^{4} \mathrm{I}_{15 / 2}$.

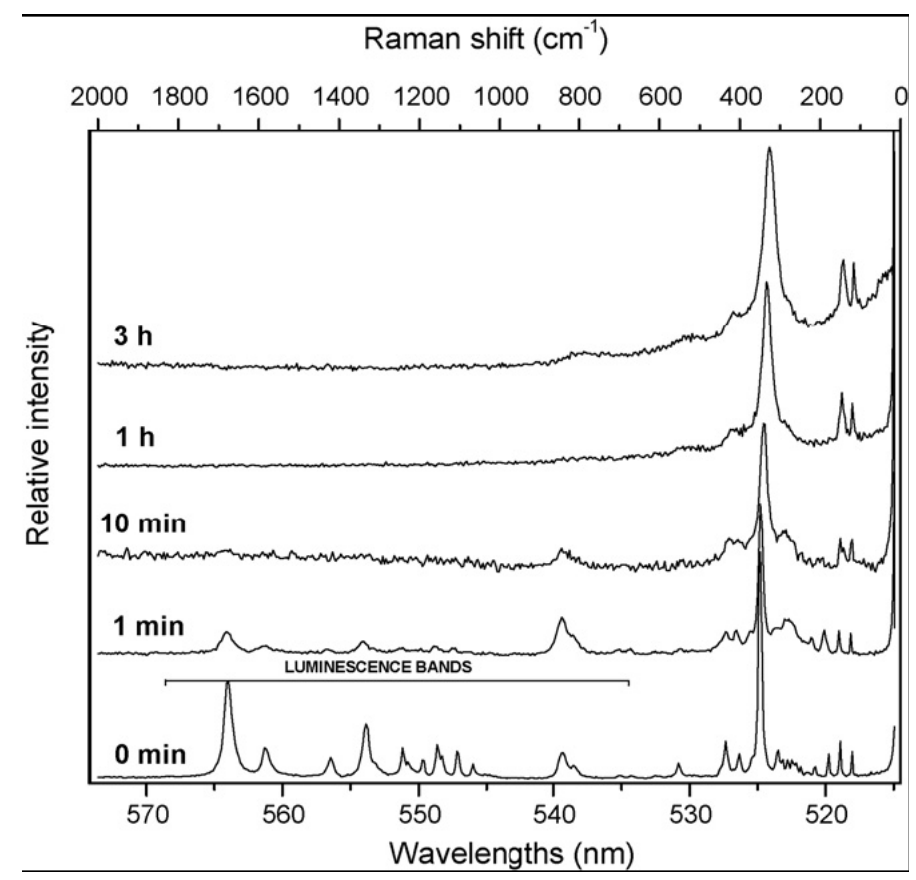

Fig. 4. Spectra of the untreated and milled $\mathrm{Y} 2 \mathrm{O} 3$ powders. Milling times are denoted above spectra.

Table 1

Band position and fool with half maximum (FWHM) determined by Lorencian fit

\begin{tabular}{|c|c|c|}
\hline Sample & Raman band position $/ \mathrm{cm}^{-1}(\mathrm{Fg}+\mathrm{Ag}$ symmetry mode) & $\mathrm{FWHM} / \mathrm{cm}^{-1}$ \\
\hline Y-0 & 381 & 10 \\
\hline Y-1 & 379 & 12 \\
\hline Y-10 & 371 & 21 \\
\hline Y-60 & 362 & 28 \\
\hline Y-180 & 355 & 38 \\
\hline
\end{tabular}


min treatment. Lattice parameter of the cubic phase had higher value than after 1 min of milling, and the microstrain also increased, while average grain size significantly decreased compared with 1 min milled sample (Table 2). Moreover, the reflections of the monoclinic phase (space group $C 2 / m)[26]\left(\mathrm{Y}_{2} \mathrm{O}_{3}\right.$ : $\mathrm{PDF}$ 44-0399) appeared in the diffraction pattern of 10 min milled sample as denoted in Fig. 5.

The weight fraction of the monoclinic phase, calculated from XRD pattern, was $47.4 \%$ (Table 2) with average grain size of $10.2 \mathrm{~nm}$ and significant $54.9 \times 10^{-4}$ average microstrain. By prolonged milling to $1 \mathrm{~h}$ or more the weight fraction of the monoclinic phase increased, and the grain size of this phase decreased to the value of $7.9 \mathrm{~nm}$ after $3 \mathrm{~h}$ of milling. At the same time, the average microstrain of the monoclinic phase decreased. The average maximum microstrain showed opposite trend in the cubic structure and increased with increase of milling time (Table 2). The continuity of the diminution of the grains was also observed in the cubic phase of the sample. On the other hand, the lattice parameter of the cubic phase decreased after maximum value refined for 10 min milled sample.

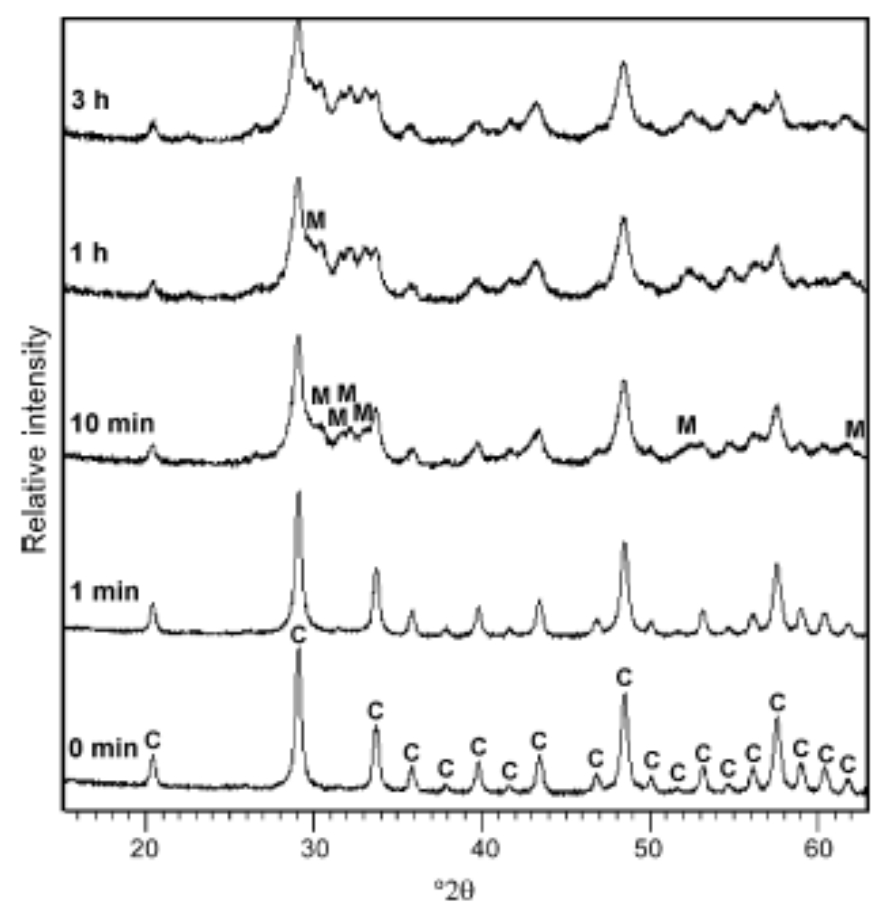

Fig. 5. XRD patterns of the untreated and milled $\mathrm{Y}_{2} \mathrm{O}_{3}$ powders. Milling times are denoted above patterns. C-cubic bixbyite structure; space group Ia3, Mmonoclinic structure; space group $C 2 / m$.

TEM was used to investigate possible influence of the nanostructural changes to the decrease of the luminescence bands intensity. The morphology of the starting and milled samples is similar due to the agglomeration of primary crystallites to a secondary structure (low magnification micrographs in Fig. 6).

However, ring patterns in SAED become more and more continuous from starting powders to powders milled during prolonged milling time, indicating the crystallites become smaller and more randomly orientated, thus producing diffraction rings. HRTEM reveals that the crystallite size of powders with prolonged milling time is smaller then $10 \mathrm{~nm}$, while the particle sizes observed at starting powder are more than $100 \mathrm{~nm}$. Only the crystallites of the cubic structure were observed in HRTEM and in SAED pattern of $1 \mathrm{~min}$ milled sample, thus indicating that phase transition to monoclinic structure did not started. Crystallites of monoclinic phase were observed in samples milled $10 \mathrm{~min}$ or longer (Fig. 6c and d). The nanosized crystallites of cubic (C) phase were still present in samples milled for longer time.

\section{Discussion}

The origin of luminescence is highly influenced by crystalchemical properties. The local crystal field at cation sites induces Stark splitting of cation electron orbitals. The symmetry of coordination polyhedra are responsible for the splitting of yttrium $3 \mathrm{~d}$ orbitals [27], but also of $4 \mathrm{f}$ orbitals in REE, which can be substituted for yttrium in the crystal structure of $\mathrm{Y}_{2} \mathrm{O}_{3}$ polymorphs. For c- $\mathrm{Y}_{2} \mathrm{O}_{3}$ two six-fold coordinated cation positions with $C_{3 \mathrm{i}}$ and $C_{2}$ symmetry exist [11]. When occupied with REE, $4 \mathrm{f}$ orbitals splits and luminescent emission takes place after laser excitation [28]. The spectroscopy experiments on $\mathrm{Y}_{2} \mathrm{O}_{3}$ 
doped with various rare earth elements $[29,30]$ ascertain that only Er-doped samples yield luminescence at the wavelength range shown in Fig. 3. Moreover, the shape and relative intensity of the luminescence bands observed in present work match with that observed in bulk and nanocrystaline $\mathrm{Y}_{2} \mathrm{O}_{3}: \operatorname{Er}^{+3}[9,13,31]$, so corresponding assignment of the bands is given in Fig. 3. Intensity of the detected luminescence bands is comparable to Raman bands, indicating that they are weak on an absolute scale. Thus, Raman spectrometer was recognized as the instrument of choice for inspection of small portion of REE ions in $\mathrm{Y}_{2} \mathrm{O}_{3}$.

\section{Table 2}

Structural data and refinement parameters for $\mathrm{Y} 2 \mathrm{O} 3$ material calculated by Rietveld refinement of XRD powder patterns

\begin{tabular}{|c|c|c|c|c|c|}
\hline Sample & Y-0 & Y-1 & Y-10 & Y-60 & Y-180 \\
\hline \multicolumn{6}{|l|}{ Phase 1} \\
\hline Space group & $I a-3(206)$ & $I a-3(206)$ & $I a-3(206)$ & $I a-3(206)$ & $I a-3(206)$ \\
\hline Lattice parameter $(\AA)$ & $10.599(1)$ & $10.601(1)$ & $10.608(1)$ & $10.607(1)$ & $10.604(1)$ \\
\hline Volume-weighted average grain size $(\mathrm{nm})$ & 24.2 & 33.5 & 17.8 & 16.6 & 16.2 \\
\hline Average maximum microstrain $e\left(\times 10^{4}\right)$ & 18.2 & 19.9 & 25.4 & 30.4 & 36.0 \\
\hline Weight fraction of phase $1(\%)$ & 100 & 100 & 52.63 & 34.74 & 33.42 \\
\hline$R_{\mathrm{wp}}(\%)$ & 14.0 & 13.9 & 10.1 & 9.6 & 8.6 \\
\hline$R_{\mathrm{B} 1}(\%)$ & 8.2 & 9.6 & 6.2 & 5.4 & 4.4 \\
\hline GoF-index & 1.8 & 2.2 & 1.5 & 1.4 & 1.4 \\
\hline \multicolumn{6}{|l|}{ Phase 2} \\
\hline Space group & & & $C 2 / m(12)$ & $C 2 / m(12)$ & $C 2 / m(12)$ \\
\hline \multicolumn{6}{|l|}{ Lattice parameters } \\
\hline$a\left(\mathrm{~A}^{\circ}\right)$ & & & $13.881(3)$ & $13.896(2)$ & $13.896(2)$ \\
\hline$b\left(\mathrm{~A}^{\circ}\right)$ & & & $3.492(1)$ & $3.494(1)$ & $3.492(1)$ \\
\hline$c\left(\mathrm{~A}^{\circ}\right)$ & & & $8.588(2)$ & $8.594(2)$ & $8.589(2)$ \\
\hline$\beta\left(\mathrm{A}^{\circ}\right)$ & & & $100.08(1)$ & $100.13(1)$ & $100.19(1)$ \\
\hline Volume-weighted average grain size (nm) & & & 10.2 & 9.1 & 7.9 \\
\hline Average maximum microstrain $e\left(\times 10^{4}\right)$ & & & 54.9 & 34.7 & 12.2 \\
\hline$R_{\mathrm{B} 2}(\%)$ & & & 6.1 & 4.5 & 4.5 \\
\hline Weight fraction of phase $2(\%)$ & & & 0047 & .465 .3 & 66.6 \\
\hline
\end{tabular}

In m- $\mathrm{Y}_{2} \mathrm{O}_{3}$ three 7-coordinated cation positions with $C_{\mathrm{s}}$ symmetry accommodate yttrium and doped REE [16]. The luminescence from REE occupying these structural positions has been also reported [17,32]. Since both structural modifications of $\mathrm{Y}_{2} \mathrm{O}_{3}$, which were observed in the present study after ballmilling, should show luminescence when doped with REE, and it is unlikely that the loss of REE occurred during the mechanical treatment, it is necessary to take into account additional structural considerations in order to explain the loss of luminescence bands.

It is very likely that the decrease in intensity of the luminescence bands as a function of the ball-milling time (Fig. 4) depends on the creation of defects and so the oxygen vacancies. Studies on $\mathrm{Y}_{2} \mathrm{O}_{3}$ thin film established that there is a significant influence of oxygen vacancies to the structure and thus electronic properties of $\mathrm{Y} 2 \mathrm{O} 3$ [27,33-36]. Namely, the introduction of oxygen vacancies leads to the distortion of $\mathrm{YO}_{6}$ octahedra in the structure of $\mathrm{c}-\mathrm{Y}_{2} \mathrm{O}_{3}$ [33]. The observed increase of microstrain caused by only $1 \mathrm{~min}$ milling (Table 2) implies increase of defects and so a variation of the amount of the oxygen vacancies in $\mathrm{c}-\mathrm{Y}_{2} \mathrm{O}_{3}$ phase. By prolonged milling, the contribution of highenergy milling also induced cubicmonoclinic $\mathrm{Y}_{2} \mathrm{O}_{3}$ transition, where $\mathrm{m}-\mathrm{Y}_{2} \mathrm{O}_{3}$ is a high-pressure modification. One oxygen is added into the first coordination shell of yttrium due to the transformation to the $\mathrm{m}-\mathrm{Y}_{2} \mathrm{O}_{3}$ with seven-fold coordination around cation sites. It has been reported that the formation of $\mathrm{m}-\mathrm{Y}_{2} \mathrm{O}_{3}$ is a preferable mechanism for accommodation of excess of the oxygen vacancies [36]. The elimination of oxygen vacancies in $\mathrm{m}-\mathrm{Y} 2 \mathrm{O} 3$ influences cation coordination polyhedra, leading to the change of crystal field, and thus causing the disappearance of Stark splitting of $\mathrm{Er}^{3+} 4 \mathrm{f}$ orbitals with relevant electron transitions responsible for luminescence. The observed decrease of average microstrain of $\mathrm{m}-\mathrm{Y}_{2} \mathrm{O}_{3}$ with prolonged milling time reflects the decrease of distortion, which is quite unusual for milling process. This could be attributed to the defects annihilation associated with accommodation of excess of the oxygen vacancies.

On the other hand increase of microstrain in $\mathrm{c}_{-} \mathrm{Y}_{2} \mathrm{O}_{3}$ phase was observed during milling (Table 2). The initial increase of the lattice parameter is encouraged by the microstrain, but after 10 min milling the decrease of the $\mathrm{c}-\mathrm{Y}_{2} \mathrm{O}_{3}$ lattice parameter is due to inbuilt of small amount of tungsten atoms (material of the mill) in the lattice, since the ionic radius of the tungsten $(0.60 \AA)$ is considerably smaller than that of yttrium $(0.90 \AA)$ and/or erbium $(0.89 \AA)$. Nevertheless, no reflection of tungsten carbide was observed in 
(a)

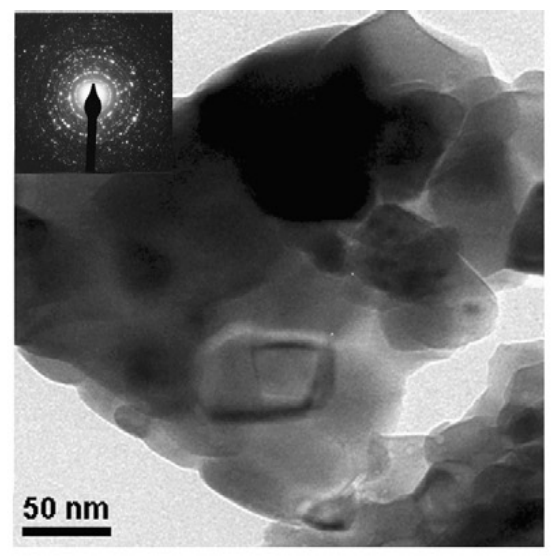

(b)

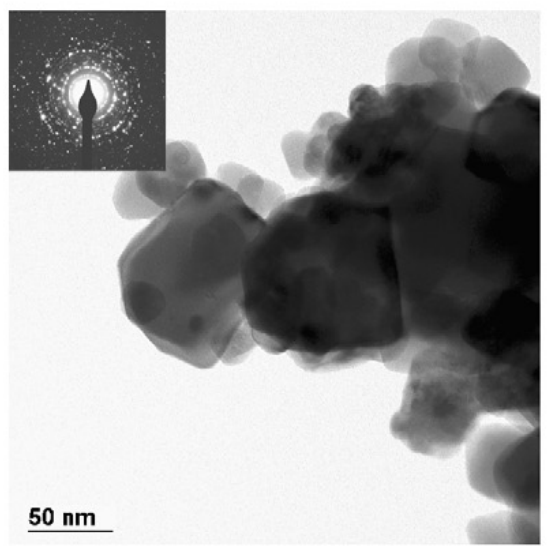

(c)

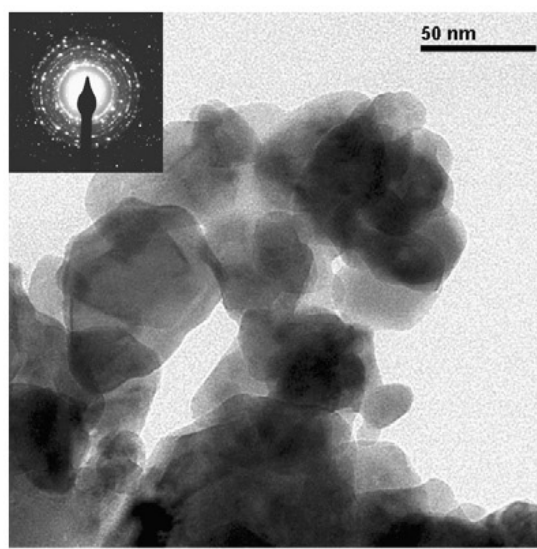

(d)

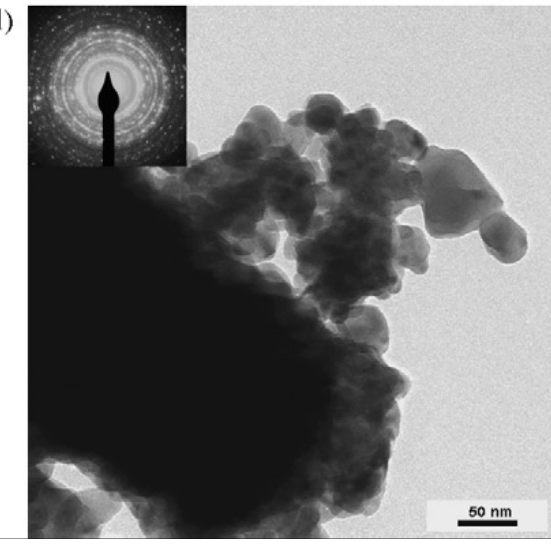

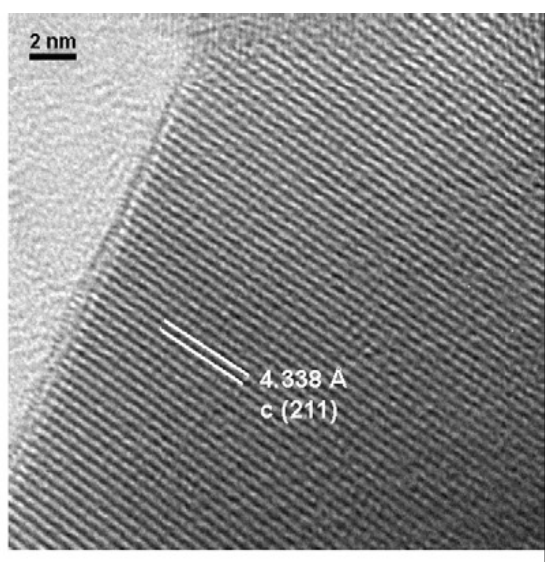
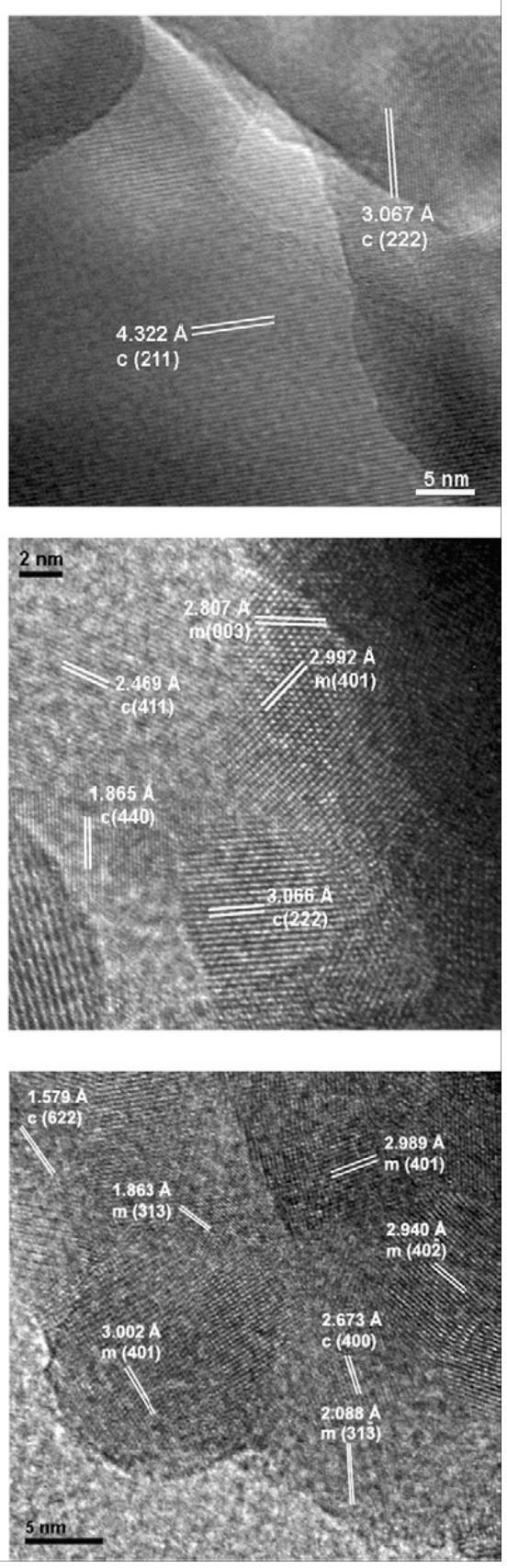

Fig. 6. TEM, HRTEM images and SAED pattern (inset) of the investigated $\mathrm{Y}_{2} \mathrm{O}_{3}$ powders: (a) starting material, material milled for: (b) $1 \mathrm{~min}$, (c) $10 \mathrm{~min}$ and (d) $60 \mathrm{~min}$. 
XRD patterns (Fig. 5), thus indicating very low contamination during mechanochemical treatment. The substitution of tungsten at the cation sites could also hinder luminescence, since it eliminated $\mathrm{Er}^{+3}$ as luminescence origin. XRD and TEM reveal the nanostructuring of the $\mathrm{Y}_{2} \mathrm{O}_{3}$ powders through high-energy ball-milling. However, reducing the particle size is unlikely the reason for the disappearance of the luminescence for the samples milled more than one hour, in which the primary particles have an averaged size of $10 \mathrm{~nm}$. A decrease of luminescence in nanosized $c-\mathrm{Y}_{2} \mathrm{O}_{3}$ was reported in literature, but is explained by the adsorbed $\mathrm{OH}^{-}$(and $\mathrm{CO}_{3}{ }^{-}$) as surface contaminants [9,31]. In our ball-milled samples no such surface adsorbents were observed because no corresponding vibration bands were recorded in RS.

\section{Conclusions}

The small amount of REE ion $(<0.01 \%)$, predominantly erbium, in commercially available $\mathrm{Y}_{2} \mathrm{O}_{3}$ powders (purity 99.99\%) was identified as origin of the luminescence bands observed by Raman spectroscopy instrumentation. The highenergy ball-milling induced the loss of luminescence upon mechanochemical treatment. The attenuation and complete removal of the luminescence in milled samples could be explained in respect of three parallel mechanisms: distortion of the lattice during mechanochemical processing inducing oxygen vacancies in the cubic phase, substitution of tungsten at the cation sites in c$\mathrm{Y}_{2} \mathrm{O}_{3}$, and incomplete phase transition of $\mathrm{Y}_{2} \mathrm{O}_{3}$ from the cubic to the monoclinic structure. The phase transition partially changes oxygen arrangemen around cation positions occupied withYand REE thus changing the crystal field around cations, which influencing Stark splitting of $4 \mathrm{f}$ orbitals in REE and respective optical transitions. The reduction of the particle size and surface adsorbed $\mathrm{OH}^{-}$as the reason for the disappearance of the luminescence during ball-milling was shown less probable. The influence of the microstructure of nanosized $\mathrm{Y}_{2} \mathrm{O}_{3}$ and so luminescence spectra evidenced in this work could affect the possible applications of $\mathrm{Y}_{2} \mathrm{O}_{3}$ doped with lanthanides.

\section{Acknowledgments}

We thank M. Stubičar for milling experiments. The work is supported by Ministry of Science, Education and Sport of the Republic of Croatia, the work in Berlin is financially supported by Max Planck Society.

\section{References}

[1] R.L. Henry, E.J. Cukauskas, S.B. Qadri, A.H. Singer, G.G. Campisi, IEEE T. Magn. 25 (2) (1989) 2352.

[2] P. Regnier,M. Sapin, C. Thomas de Montpreville, Supercond. Sci. Technol. 2 (1989) 173-177.

[3] B. Ferrari, R. Moreno, Adv. Eng. Mater. 6 (12) (2004) 969-971.

[4] M. Boaro, J.M. Vohs, R.J. Gorte, J. Am. Ceram. Soc. 86 (2003) 395-400.

[5] S. Zhang, R. Xiao, J. Appl. Phys. 83 (1998) 3842-3848.

[6] J.J. Chambers, G.N. Pearson, J. Appl. Phys. 90 (2001) 918-933.

[7] K.J. Hubbard, D.G. Schlom, J. Mater. Res. 11 (11) (1996) 2757-2776.

[8] R.J. Gaboriaud, F. Pailloux, P. Guerin, F. Paumier, Thin Solid Films 400 (2001) 106-110.

[9] F.Vetrone, J.-C. Boyer, J.A. Capobianco, A. Speghini, M. Bettinelli, Chem. Mater. 15 (2003) 2737-2743.

[10] L. Laversenne, Y. Guyot, C. Goutaudier, M.Th. Cohen-Adad, G. Boulon, Opt. Mater. 16 (2001) 475-483.

[11] F. Hanic, M. Hartmova, G.G. Knab, A.A. Uruskovkkaya, K.S. Bagdasarov, Acta Crystallogr. B 40 (1984) $76-82$.

[12] Y.N. Xu, Z. Gu, W.Y. Ching, Phys. Rev. B: Condens. Matter 56 (1997) 14993-15000.

[13] J. Silver, M.I. Martinez-Rubio, T.G. Ireland, R. Withnall, J. Phys. Chem. B 105 (2001) 7200-7204.

[14] M. Klintenberg, S. Edvardsson, J.O. Thomas, J. Alloys Compd. 275-277 (1998) 174-176.

[15] E. Husson, C. Proust, P. Gillet, J.P. Itie, Mater. Res. Bull. 34 (1999) 2085-2092.

[16] H.L. Yakel, Acta Crystallogr. B 35 (1979) 564-569.

[17] B. Bihari, H. Eilers, B.M. Tissue, J. Lumin. 75 (1997) 1-10.

[18] L.B. McCusker, R.B. Von Dreele, D.E. Cox, D. Louer, P. Scardi, J. Appl. Crystallogr. 32 (1999) 36-50.

[19] J. Rodriguez-Carvajal, FULLPROF-A Program for Rietveld Refinement, Laboratorie Leon Brillouin, CEA-Saclay, France, 2000.

[20] P. Thompson, D.E. Cox, J.B. Hastings, J. Appl. Crystallogr. 20 (1987) 79-83.

[21] Digital Micrograph 3.6.5 (1999) Gatan Inc., Pleasanton, CA, USA.

[22] J.L. Lábár, in: L. Frank, F. Ciampor (Eds.), Proceedings of the EUREM

12, vol. III, Brno, July 2000, 2000, pp. I379-I380.

[23] L. Nasdala, D.C. Smith, R. Kaindl, M.A. Ziemann, Raman spectroscopy: analytical perspectives in mineralogical research, in: A. Beran, E. Libowitzky (Eds.), Spectroscopic methods in mineralogy, vol. 6, European Mineralogical Union Notes in Mineralogy, Budapest, 2004, pp. 281-343.

[24] Y. Repelin, C. Proust, E. Husson, J.M. Beny, J. Solid State Chem. 118 (1995) 163-169. 
[25] J. Cai, C. Raptis, Y.S. Raptis, E. Anastassakis, Phys. Rev. B 51 (1995) 201-209.

[26] JCPDS International Centre for Diffraction Data, Swarthmore, PA, 1996.

[27] A. Travlos, N. Boukos, G. Apostolopoulos, A. Dimoulas, C. Giannakopoulos, Mater. Sci. Eng. B 109 (2004) 52-55.

[28] L. Laversenne, Y. Guyot, C. Goutaudier, M.Th. Cohed-Adad, G. Boulon, Opt. Mater. 16 (2001) 475-483.

[29] J. Silver, R. Withnall, Chem. Rev. 104 (2004) 2833-2855.

[30] T. Biljan, A. Gajovi'c, Z. Mei'c, E. Me`strovi'c, J. Alloys Compd. 431 (2007) 217-220.

[31] J.A. Capobianco, F. Vetrone, T. D’Alesio, G. Tessari, A. Speghini, M.

Bettinelli, Phys. Chem. Chem. Phys. 2 (2000) 3203-3207.

[32] J.F. Martel, S. Jandl, B. Viana, D. Vivien, J. Phys. Chem. Solids 61 (2000) 1455-1463.

[33] F. Jollet, C. Noguera, M. Gautier, N. Thromat, J.P. Duraud, J. Am. Ceram. Soc. 74 (2) (1991) 358-364.

[34] L.J. Alvarez, M.A. San Miguel, J.A. Odriozola, Phys. Rev. B 59 (1999) 11303-11307.

[35] F. Paumier, R.J. Gaboriaud, A.R. Kaul, Cryst. Eng. 5 (2002) 169-175.

[36] R.J. Gaboriaud, F. Paumier, F. Pailloux, L. Guerin, Mater. Sci. Eng. B 109 (2004) 34-38. 